\title{
Who Orders Screening Mammograms in Older Women with Limited Life Expectancy?
}

\author{
Nancy L. Schoenborn, MD, MHS ${ }^{\top}$, Jin Huang, MS, PhD ${ }^{\top}$, Cynthia M. Boyd, MD, MPH ${ }^{7}$, \\ Sarah Nowak, $P h D^{2}$, and Craig E. Pollack, MD, MHS ${ }^{3}$
}

${ }^{1}$ The Johns Hopkins University School of Medicine, Baltimore, MD, USA; ${ }^{2}$ RAND Corporation, Santa Monica, CA, USA; ${ }^{3}$ The Johns Hopkins University School of Public Health, Baltimore, MD, USA.

J Gen Intern Med 34(12):2720-2

DOI: $10.1007 / \mathrm{s} 11606-019-05044-0$

(C) Society of General Internal Medicine 2019

\section{INTRODUCTION}

Breast cancer screening in older women with limited life expectancy may pose more harms than benefits but many of these women still receive screening mammograms. ${ }^{1,2}$ Clinician recommendation is an important driver of screening. ${ }^{2}$ Previous surveys suggest that specialists are more likely than generalists to recommend screening mammograms for older women. ${ }^{3,4}$ With the goal of better targeting future interventions, we examined the specialties of the clinicians who referred older women for mammograms in a nationally representative cohort and whether the specialties varied depending on the women's estimated life expectancies. We then investigated whether the receipt of screening mammograms was linked with outpatient visits with different types of clinicians.

\section{METHODS}

Using data from the first wave of the National Health and Aging Trends Study (NHATS) in 2011 linked to Medicare claims, we identified women $65+$ years old without history of breast cancer who were continuously enrolled in fee-forservice Medicare from 2010 to 2013. Medicare data in the 12 months prior to the 2011 NHATS interview were used to exclude patients with breast cancer history while data in the 24 months following the 2011 NHATS interview, defined as the study period, were used to assess receipt of screening. Screening mammograms were identified using claims data. ${ }^{5}$ Ten-year mortality risks were predicted from a validated index ${ }^{6}$ using survey data (excluding $n=355$ with missing information); predicted mortality was then used to categorize women as having $<10$-year versus $>10$-year median life expectancies.

Previous Presentations N/A.

Received April 11, 2019

Accepted April 17, 2019

Published online May 14, 2019
First, we examined the specialties of the referring clinicians associated with a patient's screening mammogram on Medicare claim. We compared the distribution of the referring clinicians' specialties among women with $<10$-yearpredicted life expectancy and among women with $>10$-yearpredicted life expectancy using the chi-square test. Second, we used a logistic regression model to assess the association of different types of outpatient visits with breast cancer screening. The dependent variable was receipt of screening mammography. Independent variables included whether the patient had a primary care provider, a gynecology visit, and the total number of outpatient visits with all other types of clinicians, all within the 12 months prior to the study period. The model controlled for predicted life expectancy $(<10$ years versus $>$ 10 years), age, and race. We tested for interaction between predicted life expectancy and each of the three independent variables.

\section{RESULTS}

Among the 2041 women in our cohort, $48.0 \%$ received at least one screening mammogram during the study period, with screening rate of $60.2 \%$ among women with $>10$-yearpredicted life expectancy and $27.0 \%$ among women with $<$ 10 -year-predicted life expectancy (Table 1). Among the women who received screening, specialty of the referring clinician for the screening mammogram was available for 794 (94.2\%) women. For both life expectancy groups, the most common clinician specialties associated with screening mammogram referrals were internal medicine, followed by family medicine, and obstetrics/gynecology (Table 1), with no significant difference in the distribution of clinician specialties between the two groups $(p=0.30)$.

In the adjusted regression model, we found that visiting a gynecologist was associated with increased odds of receiving screening mammograms (odds ratio [OR] 2.28, 95\% confidence interval $[\mathrm{CI}] 1.48,3.51, p<0.001)$ and this association did not significantly differ by the patient's predicted life expectancy (interaction term $p=0.25$ ). We found having a primary care provider (PCP) was also associated with increased odds of receiving screening mammograms but the effect differed by the patients' 
Table 1 Participant Characteristics, Screening Mammogram Rates, and Clinician Specialties Associated with Screening Mammogram Referrals Among the 2041 Women Included in the Study

\begin{tabular}{|c|c|c|c|}
\hline & $\begin{array}{l}>10 \text {-year-predicted life } \\
\text { expectancy* }(n=1068)\end{array}$ & $\begin{array}{l}<10 \text {-year-predicted life } \\
\text { expectancy* }(n=973)\end{array}$ & $p$ \\
\hline Age, mean (SE) & $72.71(0.17)$ & $81.46(0.32)$ & $<0.001$ \\
\hline \multicolumn{4}{|l|}{ Race } \\
\hline Black, non-Hispanic & $7.1 \%$ & $8.7 \%$ & \multirow{3}{*}{0.092} \\
\hline Hispanic & $3.9 \%$ & $5.9 \%$ & \\
\hline Other & $3.0 \%$ & $2.5 \%$ & \\
\hline \multicolumn{4}{|l|}{ Self-rated health } \\
\hline Good & $31.7 \%$ & $31.9 \%$ & \multirow{3}{*}{$<0.001$} \\
\hline Fair & $11.9 \%$ & $31.8 \%$ & \\
\hline Poor & $1.5 \%$ & $15.1 \%$ & \\
\hline Has primary care provider ${ }^{\dagger}$ & $76.9 \%$ & $83.2 \%$ & $<0.001$ \\
\hline Visited a gynecologist in 12 months prior & $12.3 \%$ & $5.7 \%$ & $<0.001$ \\
\hline Number of outpatient visits to all other types of clinicians in 12 months prior & $3.14(0.13)$ & $4.60(0.21)$ & $<0.001$ \\
\hline Screening rate overall & $60.2 \%$ & $27.0 \%$ & $<0.001$ \\
\hline No visit & $57.4 \%$ & $26.4 \%$ & $\begin{array}{l}<0.001 \\
<0.001\end{array}$ \\
\hline \multicolumn{4}{|c|}{ Specialties of clinicians associated with screening mammogram referrals among women who were screened } \\
\hline Family medicine & $30.9 \%$ & $29.6 \%$ & \multirow[t]{5}{*}{0.30} \\
\hline Internal medicine & $33.4 \%$ & $35.0 \%$ & \\
\hline Other primary care $\S$ & $7.9 \%$ & $10.3 \%$ & \\
\hline Obstetrics/gynecology & $18.3 \%$ & $13.3 \%$ & \\
\hline All other specialties & $9.5 \%$ & $11.9 \%$ & \\
\hline
\end{tabular}

All percentages are weighted

*Using the mortality risk index developed by Cruz et al., a median life expectancy of $>10$ years is defined as a $<50 \%$ mortality risk over 10 years; a median life expectancy of $<10$ years is defined as a $>50 \%$ mortality risk over 10 years

${ }^{+}$Having a primary care provider is defined as (a) self-reporting a "usual source of care" in the NHATS interview and (b) having at least one primary care type visit with a clinician in primary care specialties (general practice, family practice, internal medicine, geriatric medicine) in the 12 months previous to the study period. Primary care type visit is defined in the claims per Center for Medicare \& Medicaid Services (http://hhs.com/assets/docs/ 2017-14639.pdf\#page=478, accessed 4/11/2019)

${ }^{7}$ Specialty of the referring clinicians for screening mammograms was not available for 47 (5.8\%) of the women. Proportion of missing data did not differ by predicted life expectancy: 33 (5.6\%) among > 10-year-predicted life expectancy and 14 (6.5\%) among < 10-year-predicted life expectancy

\$ "Other primary care" clinicians included physicians in general practice, geriatric medicine, and nurse practitioners and physician assistants in primary care specialities as defined per Romaire MA, Haber SG. Wensky SG, McCall N. Primary care and specialty providers: an assessment of continuity of care, utilization, and expenditures. Med Care. 2014;52(12):1042-9

predicted life expectancies (interaction term $p=0.04$ ). In women with $>10$-year-predicted life expectancy, having a PCP was associated with OR 3.27 of receiving screening mammograms $(95 \%$ CI $2.31,4.64)$ whereas in women with $<10$-year-predicted life expectancy, this effect was smaller with OR 1.84 (95\% CI 1.13, 3.00). The number of other types of outpatient visits was not independently associated with receipt of screening mammograms (OR 1.01 per visit, 95\% CI 0.99, 1.04, $p=0.32$ ).

\section{DISCUSSION}

In a national representative cohort of older women, we found that PCPs and gynecologists were associated with most of the screening mammogram referrals and, correspondingly, having a PCP and visiting a gynecologist were both independently associated with higher screening rates. Interventions that target both types of clinicians are likely to be more effective than those targeting primary care providers alone. Interestingly, the effect of having a PCP differed by life expectancy and may suggest that PCPs are, to some extent, taking into account the patients' life expectancies in their breast cancer screening practices.

Funding/Support: Dr. Schoenborn was financially supported by a Cancer Control Career Development Award from the American Cancer Society (CCCDA-16-002-01) and a career development award from the National Institute on Aging (K76AG059984). Dr. Boyd was financially supported by 1 K24AG056578 from the National Institute on Aging.

Corresponding Author: Nancy L. Schoenborn, MD, MHS; The Johns Hopkins University School of Medicine, Baltimore, MD, USA (e-mail: nancyli@jhmi.edu).

Author Contributions Dr. Schoenborn had full access to all of the data in the study and takes responsibility for the integrity of the data and the accuracy of the data analysis.

Study concept and design: Schoenborn, Huang, Boyd, Pollack.

Data analysis and interpretation: Schoenborn, Huang, Boyd, Nowak, Pollack.

Preparation and review of the manuscript: Schoenborn, Huang, Boyd, Nowak, Pollack 


\section{Compliance with Ethical Standards:}

Conflict of Interest: The authors declare that they do not have a conflict of interest. Dr. Pollack has stock ownership in Gilead Pharmaceuticals. We do not believe this has resulted in any conflict with the design, methodology, or results presented in this manuscript. Dr. Cynthia Boyd received a small payment from UptoDate for having $\mathrm{co}^{-}$ authored a chapter on Multimorbidity; we do not believe this has resulted in any conflict with the design, methodology, or results presented in this manuscript.

Disclaimer: The funding sources had no role in the design, methods, subject recruitment, data collections, analysis, and preparation of paper.

\section{REFERENCES}

1. Royce TJ, Hendrix LH, Stokes WA, et al. Cancer screening rates in individuals with different life expectancies. JAMA Intern Med. 2014;174(10): 1558-65.
2. Schonberg MA, Breslau ES, McCarthy EP. Targeting of mammography screening according to life expectancy in women aged 75 and older. J Am Geriatr Soc. 2013;61(3):388-395.

3. Radhakrishnan A, Nowak SA, Parker AM, Visvanathan K, Pollack CE. Physician breast cancer screening recommendations following guideline changes: results of a national survey. JAMA Intern Med. 2017;177(6):877878.

4. Leach CR, Klabunde CN, Alfano C, Smith JL, Rowland JH. Physician over-recommendatoin of mammography for terminally ill women. Cancer. 2012;118(1):27-37

5. Fenton JJ, Zhu W, Balch S, et al. Distinguishing screening from diagnostic mammograms using medicare claims data. Med Care. 2014;52(7): e44-51.

6. Cruz M, Covinsky K, Widera EW, et al. Predicting 10-year mortality for older adults. JAMA. 2013;309(9):874-876.

Publisher's Note Springer Nature remains neutral with regard to jurisdictional claims in published maps and institutional affiliations. 